\title{
Roles of Unsaturated Polyester in the Epoxy Matrix System
}

\author{
Soo-Jin Park, ${ }^{\dagger}$ Won-Bae Park, and Jae-Rock LeE \\ Advanced Materials Div., Korea Research Institute of Chemical Technology, \\ P.O. Box 107, Yusong, Taejon 305-600, Korea
}

(Received April 20, 1998)

\begin{abstract}
A study of the interpenetrating polymer network (IPN) as a polymer blend matrix was carried out using different compositions of unsaturated polyester (UP) to epoxy (EP) resins. It was observed that $5 \mathrm{wt} \%$ UP in the blend provides maximum mechanical properties, particularly the impact strength for optimum casting. Fourier transform infrared (FT-IR) spectroscopy was used to investigate the intermolecular hydrogen bonding and functional group change. In this work, changes of physical property, e.g., viscosity and specific component of interfacial tension were evaluated before and after cure, respectively. Increase of the physical properties was observed in $5 \mathrm{wt} \%$ UP in the blend, probably due to the effects of hydrogen bonding, resulting in higher toughness properties of the casting specimens.

KEY WORDS Interpenetrating Polymer Network/Epoxy/Unsaturated Polyester/Viscosity/Interfacial Tension / Mechanical Properties
\end{abstract}

Epoxy resins have been largely used in a matrix for fiber reinforced plastic (FRP) composites due to their excellent thermo-mechanical properties, thermal stability, chemical resistance, electrical properties and dimensional stability. ${ }^{1}$ In real application, a study of the improvement of matrix resin properties is important in the development of high performance composites, together with studies of high strength/modulus fibers and fiber-matrix interface. ${ }^{2}$ Although numerous chemical modifications on epoxy resins have been reported, the interpenetrating polymer networks (IPNs) by introducing some selective moieties may be economically considered as a physical interlocking system for desired properties. ${ }^{3,4}$

IPNs are special blends defined as a mixture of two or more cross-linked polymer networks without any chemical combination between polymer chains. ${ }^{5}$ During cure, network interlocking between two different polymers takes place and affects the physical properties of blends, such as viscosity ${ }^{6}$ and interfacial tension. ${ }^{7}$

In the present work, an IPN blend system of epoxy resin (EP) and unsaturated polyester resin (UP) was prepared as different compositions of UP in the blend. Then, we report the effects of network interlocking and intermolecular interaction on viscosity change and interfacial tension during IPN formulation. The final mechanical properties are discussed with different compositions of UP in the blends, particularly impact strength for the optimum casting.

\section{EXPERIMENTAL}

\section{Materials and Sample Preparation}

Epoxy resin used in this experiment was diglycidylether of bisphenol A (DGEBA, YD-114, supplied from Kukdo Chem. Co. of Korea). Epoxide equivalent weight of DGEBA was $190-210 \mathrm{~g} \mathrm{eq}^{-1}$ and the density was 1.16 $\mathrm{g} \mathrm{cm}^{-3}$ at $25^{\circ} \mathrm{C}$. Triethylene tetramine (TETA) was used as hardener for DGEBA. UP resin was orthophthalic acid type resin (R-235, supplied from Seiwon Chem. Co. of Korea). Methyl ethyl ketone peroxide

\footnotetext{
† To whom all correspondence should be addressed.
}

(MEKP) in the presence of cobalt-octoate as accelerator was used as the free radical initiator for polymerization of UP resin. DGEBA and UP structures are shown in Figure 1.

IPN blend casting of EP and UP resins were prepared with different compositions of UP corresponding to 0 , $2,5,10$, and $100 \mathrm{wt} \%$, in the presence of calculated amounts of hardener $(20 \mathrm{phr}$ ), accelerator (about $0.025 \mathrm{phr})$ and initiator $(0.5 \mathrm{phr})$ into the mold space. The curing of each resin composition was done in a laboratory at room temperature for $72 \mathrm{~h}$.

\section{Measurements}

The viscosity of blend resins at $30^{\circ} \mathrm{C}$ was monitored using parallel plate geometry on Physica (Rheo Lab. MC10). Gap size between the plates was $0.5 \mathrm{~mm}$ and shear rate was $0.5 \mathrm{~s}^{-1}$.

Contact angles were measured using the sessile drop method on a Rame-Hart goniometer. Five $\mu$ l wetting liquids were used for each measurement at $20 \pm 1^{\circ} \mathrm{C}$. Contact angle measurements were performed within $5 \mathrm{~s}$ of contact for the critical surface tension. For this work, interfacial (or surface) tension and London dispersive and specific (or polar) components for the wetting liquids are shown in Table I and were used for the evaluation of surface free energies of casting surfaces. Wetting liquids used for contact angle measurements were water ${ }^{8}$ and diiodomethane. ${ }^{9}$

Infrared spectra of the casting samples were measured with a FT-IR spectroscopy (Digital FTS-80, Bio-Rad). Scans were from 400 to $4000 \mathrm{~cm}^{-1}$ and required $40 \mathrm{~s}$ to be completed.

\section{Mechanical Properties and Microscopic Analysis}

Tensile and flexural properties of the casting specimens were carried out by an Instron \#1125, and a plastic impact tester according to ASTM D256 measured the Izod impact strengths. Flexural properties were characterized by three-point bending test according to ASTM D790 with span-to-depth ratio of $16: 1$ (cross head speed (c.h.s.) $=1.3 \mathrm{~mm} \mathrm{~min}^{-1}$ ). Fracture surfaces of the blends were observed using a scanning electron microscopy 


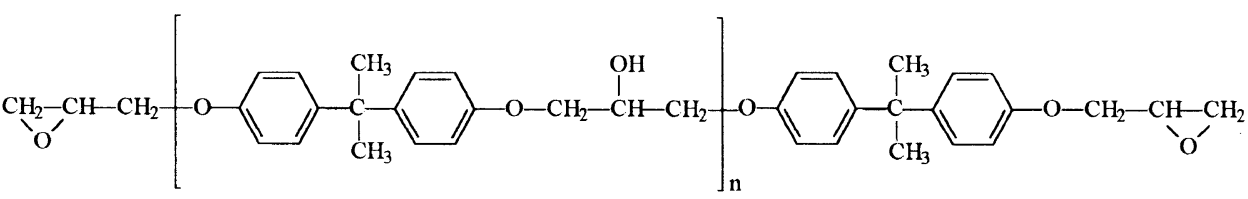

\section{DGEBA}<smiles>CCC(C)OC(=O)c1ccccc1C(=O)OCC(C)OC(=O)CC(=O)OC(C)C(C)CO</smiles>

\section{UP}

Figure 1. Chemical structure of DGEBA and UP.

Table I. Surface tension $\left(\gamma_{\mathrm{L}}\right)$ and London dispersive $\left(\gamma_{\mathrm{L}}^{\mathrm{L}}\right)$ and specific $\left(\gamma_{\mathrm{L}}^{\mathrm{SP}}\right)$ components of wetting liquids (subscript: L) measured at $20^{\circ} \mathrm{C}$

\begin{tabular}{lccc}
\hline Wetting liquids & $\gamma_{\mathrm{L}}^{\mathrm{L}} / \mathrm{mJ} \mathrm{m}^{-2}$ & $\gamma_{\mathrm{L}}^{\mathrm{SP}} / \mathrm{mJ} \mathrm{m}^{-2}$ & $\gamma_{\mathrm{L}} / \mathrm{mJ} \mathrm{m}^{-2}$ \\
\hline Water & 21.8 & 51.0 & 72.8 \\
Diiodomethane & 50.42 & 0.38 & 50.8 \\
\hline
\end{tabular}

(SEM).

\section{RESULTS AND DISCUSSION}

\section{Viscosity and Interfacial Tension}

In the IPN system, the cross-linking between DGEBA and UP would be considered as a physical or intermolecular interlocking rather than chemical combination. Two different curing agents are simultaneously used as hardeners for DGEBA and free radical initiator for UP polymerization, which can prevent the direct chemical reaction between DGEBA and UP chains. So, it is necessary to understand the roles of physical interactions of two constitutive elements. In this work, the viscosity and interfacial tension of the blends are evaluated before and after cure. Figure 2 shows the nonlinear relationship of viscosity change versus UP content in the blends used spline plot. $5 \mathrm{wt} \%$ UP in the blend provides maximum viscosity changes. The viscosity of the blends containing up to $5 \mathrm{wt} \%$ UP may be concerned with physical or intermolecular H-bond formations between DGEBA and UP. This is evident from the shift of carbonyl absorption in the IR spectra as shown in Figure 3. The original carbonyl peak of the UP occurs at $1729 \mathrm{~cm}^{-1}$. Upon the addition of $5 \mathrm{wt} \%$ UP, the carbonyl peak shifts to higher wave number at $1731.8 \mathrm{~cm}^{-1}$. The $\mathrm{OH}$ end group of the UP can physically interact with the epoxide group of DGEBA to $\mathrm{H}$-bonded. ${ }^{6}$ However, increasing UP in the blend reduces part of the original network interlocking of DGEBA,

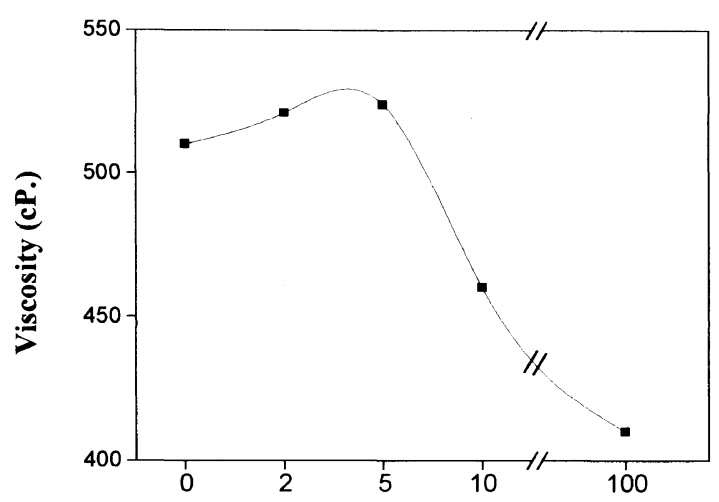

Composition of Unsaturated Polyester (wt \%)

Figure 2. Viscosity change in the blend system with the composition of UP.

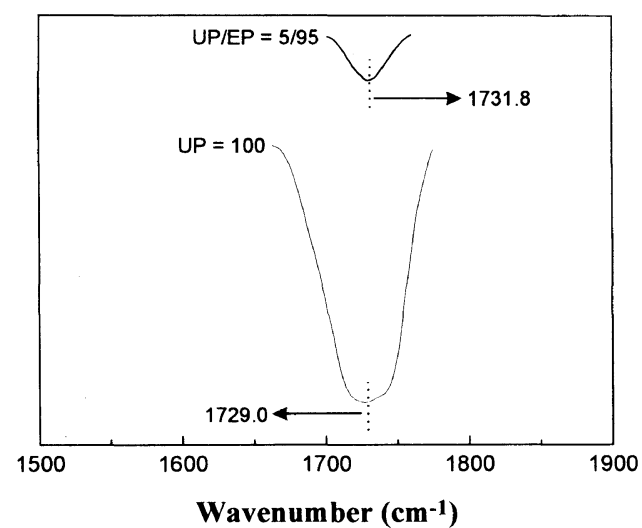

Figure 3. Shift of IP peak for carbonyl absorption in the blend system.

resulting in lower viscosity of the system, as shown in Figure 2.

The adsorption, wettability, adhesion and morphology of the component phases are greatly affected by the interfacial or surface free energies, which is important for evaluating the physical and mechanical properties of 


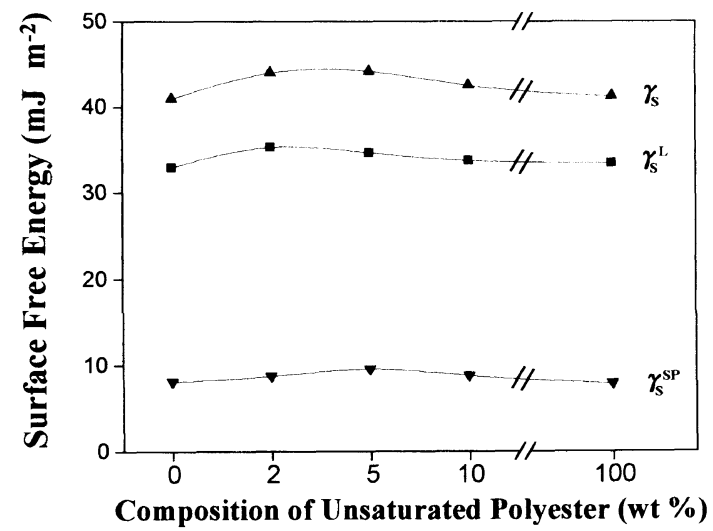

Figure 4. London dispersive $\left(\gamma_{\mathrm{S}}^{\mathrm{L}}\right)$, specific $\left(\gamma_{\mathrm{S}}^{\mathrm{SP}}\right)$, and total $\left(\gamma_{\mathrm{s}}\right)$ surface free energies of the blend system with the composition of UP.

a multiphase polymer blend system. ${ }^{7,10}$ In the early 1960 s, Fowkes ${ }^{11}$ introduced the concept of surface free energy, $\gamma$, which can be resolved into a London dispersive component (superscript: L) and specific (or polar, SP) component:

$$
\gamma=\gamma^{\mathrm{L}}+\gamma^{\mathrm{SP}}
$$

Here, $\gamma^{\mathrm{L}}$ describes the London attraction of van der Waals force and $\gamma^{\mathrm{SP}}$ ascribes all other nondispersive component of physical interactions (Debye, Keesom of van der Waals, $\mathrm{H}$-bonding, and other small polar effects).

During equilibrium contact angle (abbreviated $\theta$ here) measurement for a liquid drop on an ideally smooth and homogeneous solid surfaces, Owen and Wendt ${ }^{12}$ and $\mathrm{Wu}^{13}$ extended the Fowkes' concept using geometric mean, as follows:

$$
\gamma_{\mathrm{L}}(1+\cos \theta)=2\left(\gamma_{\mathrm{L}}^{\mathrm{L}} \cdot \gamma_{\mathrm{S}}^{\mathrm{L}}\right)^{1 / 2}+2\left(\gamma_{\mathrm{L}}^{\mathrm{SP}} \cdot \gamma_{\mathrm{S}}^{\mathrm{SP}}\right)^{1 / 2}
$$

where subscripts $\mathrm{L}$ and $\mathrm{S}$ are liquid and solid states, respectively.

In more practical relationship based on two simultaneous liquids of widely different properties on solid surfaces, e.g., water and diiodomethane for largely polar and nonpolar liquids, respectively, $\gamma_{\mathrm{S}}^{\mathrm{L}}$ and $\gamma_{\mathrm{S}}^{\mathrm{SP}}$ can be solved according to eq 2 :

$\gamma_{\mathrm{S}}^{\mathrm{L}}=\frac{1}{4}\left[\frac{\left(1+\cos \theta_{1}\right) \gamma_{1} \cdot\left(\gamma_{2}^{\mathrm{SP}}\right)^{1 / 2}-\left(1+\cos \theta_{2}\right) \gamma_{2} \cdot\left(\gamma_{1}^{\mathrm{SP}}\right)^{1 / 2}}{\left(\gamma_{1}^{\mathrm{L}} \cdot \gamma_{2}^{\mathrm{SP}}\right)^{1 / 2}-\left(\gamma_{2}^{\mathrm{L}} \cdot \gamma_{1}^{\mathrm{SP}}\right)^{1 / 2}}\right]^{2}$

$\gamma_{\mathrm{S}}^{\mathrm{SP}}=\frac{1}{4}\left[\frac{\left(1+\cos \theta_{2}\right) \gamma_{2} \cdot\left(\gamma_{1}^{\mathrm{L}}\right)^{1 / 2}-\left(1+\cos \theta_{1}\right) \gamma_{1} \cdot\left(\gamma_{2}^{\mathrm{L}}\right)^{1 / 2}}{\left(\gamma_{1}^{\mathrm{L}} \cdot \gamma_{2}^{\mathrm{SP}}\right)^{1 / 2}-\left(\gamma_{2}^{\mathrm{L}} \cdot \gamma_{1}^{\mathrm{SP}}\right)^{1 / 2}}\right]^{2}$

The results of interfacial tensions or surface free energies of the blend systems studied are shown in Figure 4. Five $\mathrm{wt} \%$ UP in the blend gives maximum interfacial tension which is mainly due to its higher specific component, $\gamma_{\mathrm{S}}^{\mathrm{SP}}$. This interfacial tension increase can be attributed to intermolecular H-bonding between DGE$\mathrm{BA}$ and UP that is one of the specific component of surface free energies, as evidenced from the IR spectra in Figure 3.

\section{Mechanical Properties}

For rectangular cross-sections of the blends, flexural

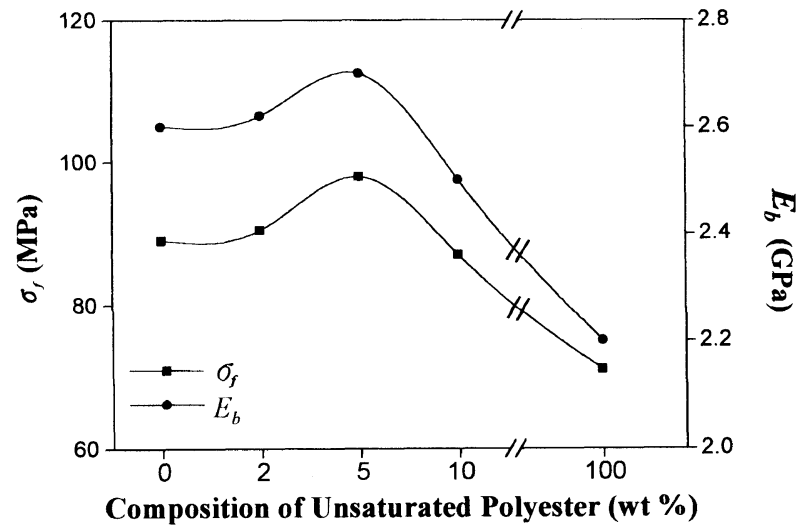

Figure 5. Flexural strength $\left(\sigma_{\mathrm{f}}\right)$ and elastic modulus in flexure $\left(E_{\mathrm{b}}\right)$ with the composition of UP.

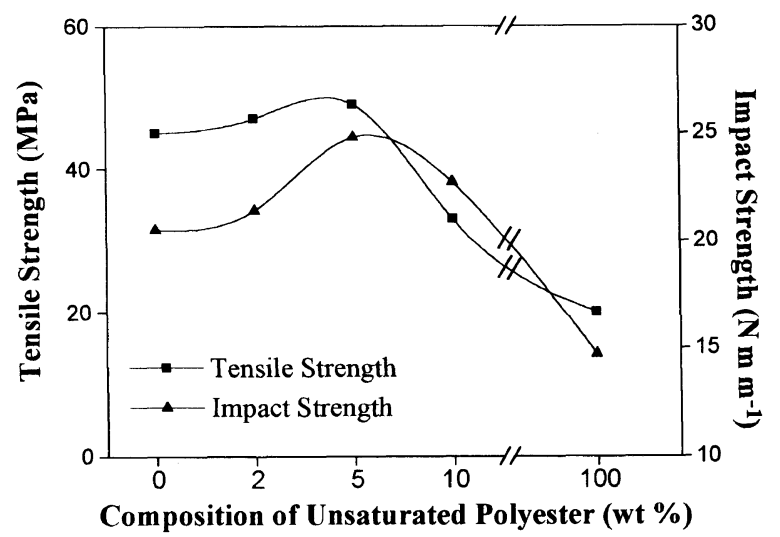

Figure 6. Tensile strength and impact strength of the blend system with the composition of UP.

strength $\left(\sigma_{\mathrm{f}}\right)$ and elastic modulus in flexure $\left(E_{\mathrm{b}}\right)$ are studied as a function of composition of UP in the blends. $\sigma_{\mathrm{f}}$ and $F_{\mathrm{b}}$ of the blends carried out from three-point bending test were calculated as:

$$
\begin{gathered}
\sigma_{\mathrm{f}}=\frac{3}{2} \frac{P L}{b d^{2}} \\
E_{\mathrm{b}}=\frac{L^{3}}{4 b d^{3}} \cdot \frac{\Delta P}{\Delta m}
\end{gathered}
$$

where $P$ is the applied fracture force $[\mathrm{N}], L$ distance between the supports [m], $b$ width of the specimen [m], $d$ thickness of the specimen $[\mathrm{m}], \Delta P$ change in fracture force in the linear portion of the load-deflection curve $[\mathrm{N}]$ and $\Delta m$ change in deflection corresponding to $\Delta P$ [m].

Figures 5 and 6 show flexural strength - the elastic modulus in flexure and tensile strength -impact strength versus the composition of UP in the blends studied. All results indicate $5 \mathrm{wt} \%$ UP in the blend provides an optimum casting, especially impact strength. Mukherjee and Saraf ${ }^{15}$ reported an expression for the distribution of free volume in a polyester/EP blend system. In the present work, the addition of small moieties of UP leads to the reduction of the free volume in and around the DGEBA network, and finally results in redistribution of free volume within the blend system. Thereby, network interlocking between DGEBA and UP takes place and the matrix becomes more rigid due to the restriction in 


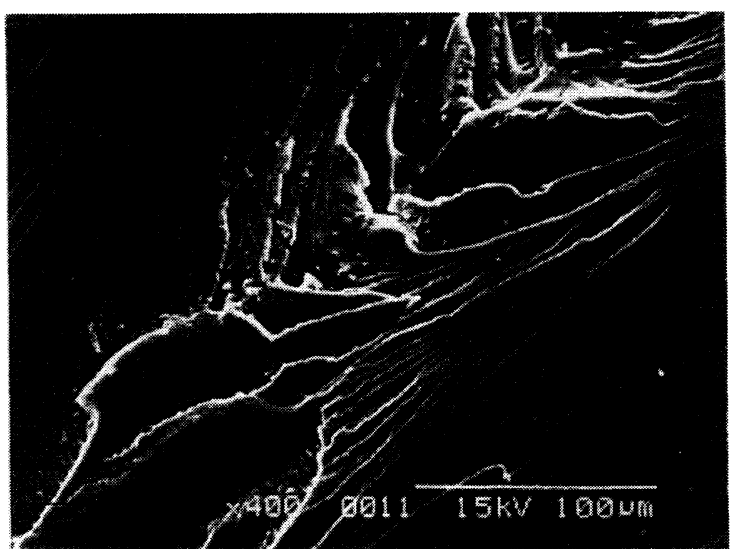

(a)

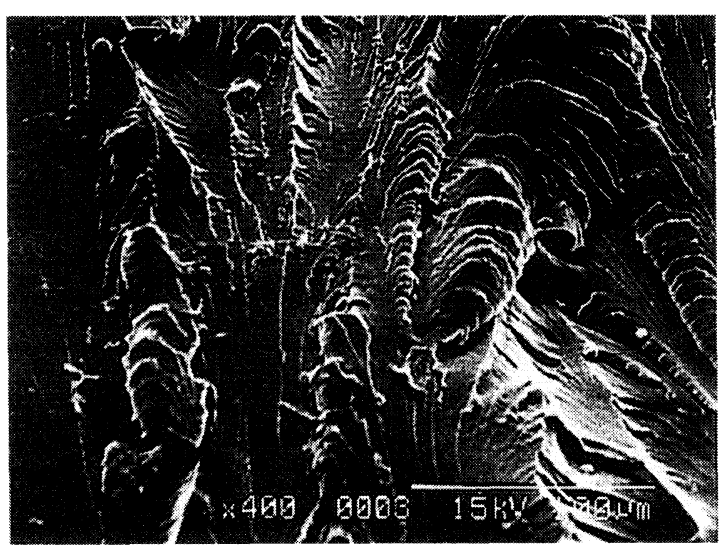

(b)

Figure 7. Fracture surface of the blend system after impact tests. (a) $0 \mathrm{wt} \%$ UP; (b) $5 \mathrm{wt} \%$ UP.

the chain mobility. This can be interpreted as the effect of H-bonding between the $\mathrm{OH}$ end group of UP and epoxide group of DGEBA, resulting in much improvement of impact properties more than the other mechanical properties studied. Impact properties of the polymeric materials are directly related to the overall toughness of the material which can be defined as the ability of the polymer to absorb applied energy. ${ }^{16}$ The fracture surfaces of the casting specimen after impact tests are shown in Figure 7. Five wt \% UP in the blend shows more ductile than pure DGEBA-cured, resulting in better mechanical properties of the blend.

\section{CONCLUSION}

In this work, a DGEBA/UP blend system based on viscosity and interfacial tension was studied for optimum casting of the specimens. The presence of intermolecular $\mathrm{H}$-bond between the $\mathrm{OH}$ end group of UP and epoxide group of DGEBA was observed in terms of FT-IR and increases good network interlocking in the IPN formation, for better mechanical properties of the casting. Five wt $\%$ UP in the blends appears to increase the $\mathrm{H}$-bond or specific component of the surface free energy, which is related to the redistribution of free volume in the blend system, effectively resulting in optimum toughness properties of the castings.

\section{REFERENCES}

1. R. E. Lyon and D. L. Schumann, Polym. Compos., 13, 1 (1992).

2. S. J. Park and J. R. Lee, J. Mater. Sci., 33, 647 (1998).

3. T. G. Fox and P. J. Flory, J. Am. Chem. Soc., 70, 2384 (1948).

4. G. Odin, "Principle of Polymerization," 3rd ed, John Wiley \& Sons, New York, N.Y., 1993.

5. D. S. Lee and S. C. Kim, Macromolecules, 18, 2173 (1985).

6. M. S. Lin, R. J. Chang, T. Yang, and Y. F. Shih, J. Appl. Polym. Sci., 55, 1607 (1995).

7. S. Wu, in "Polymer Blends," D. R. Paul and S. Newman, Ed., Academic Press, New York, N.Y., 1978, Chapter 6.

8. D. H. Kaelble and K. C. Uy, J. Adhesion, 2, 50 (1970).

9. M. Morra, E. Occhiello, and F. Garbassi, J. Colloid Interface Sci., 164, 325 (1994).

10. S. J. Park and J. B. Donnet, J. Colloid Interface Sci., in press (1998).

11. F. M. Fowkes, J. Phys. Chem., 66, 382 (1962)

12. D. K. Owens and R. C. Wendt, J. Appl. Polym. Sci., 13, 1741 (1969).

13. S. Wu, "Polymer Interface and Adhesion," Marcel Dekker, New York, N.Y., 1982.

14. M. S. Lin and R. J. Chang, J. Appl. Polym. Sci., 46, 815 (1992).

15. G. S. Mukherjee and M. N. Saraf, J. Appl. Polym. Sci., Polym. Phys., 33, 855 (1995).

16. V. Shah, "Handbook of Plastics Testing Technology," John Wiley \& Sons, New York, N.Y., 1984. 